\title{
Spondyloarthritis Associated with Inflammatory Bowel Disease: Study of 15 Observations in Guinea
}

\author{
Condé Kaba1,2, Awada Mohamed1, Carlos Othon Guelngar², Adjibaye Emmanuel ${ }^{3}$, \\ Sanni Yaya Aminou ${ }^{2}$, Mamadou Hady Diallo1, Touré Moriba', Kamissoko Aly Badra', \\ Konaté Ibrahima Sory², Fodé Abass Cissé2
}

\author{
${ }^{1}$ Department of Rheumatology, Academic Hospital, University of Conakry, Guinea \\ ${ }^{2}$ Department of Neurology, Academic Hospital, University of Conakry, Guinea \\ ${ }^{3}$ Department of infectious disease, Reference Hospital, Ndjamena, Chad \\ Email: Condekba95@yahoo.fr, awadamohamed2@gmail.com, car1325@yahoo.f, eadjibaye@gmail.com, sayamine2@gmail.com, \\ touremoriba@yahoo.fr, hadyd08@gmail.com, ibrahimasorry8224@gmail.com, abass3002yahoo.fr
}

How to cite this paper: Kaba, C., Mohamed, A., Guelngar, C.O., Emmanuel, A., Aminou, S.Y., Diallo, M.H., Moriba, T., Badra, K.A., Sory, K.I. and Cissé, F.A. (2021) Spondyloarthritis Associated with Inflammatory Bowel Disease: Study of 15 Observations in Guinea. Open Journal of Rheumatology and Autoimmune Diseases, 11, 89-95.

https://doi.org/10.4236/ojra.2021.112011

Received: January 21, 2021

Accepted: May 28, 2021

Published: May 31, 2021

Copyright $\odot 2021$ by author(s) and Scientific Research Publishing Inc. This work is licensed under the Creative Commons Attribution International License (CC BY 4.0).

http://creativecommons.org/licenses/by/4.0/

(c) (i) Open Access

\begin{abstract}
Objective: Rheumatologic disorders of chronic inflammatory bowel disease (IBD) and reactive arthritis with a digestive origin are part of the spondyloarthritis family. In black Africa, the prevalence of SpA associated with IBD is not clearly established. Thus the objective of our study was to describe the clinical and radiological characteristics of spondyloarthritis associated with IBD. Patients and Method: We carried out a prospective study in the rheumatology department of CHU Ignace Deen between January and December 2019. The diagnosis of SpA was based on clinical and biological arguments in accordance with the criteria of Amor and ASAS. Results: Fifteen observations of spondyloarthritis associated with IBD were collected in patients mean age 52 years with extremes of 32 and 65 years. $9(53.33 \%)$ were female. Ten patients had Crohn's disease (CD) and 5 had ulcerative colitis (UC). The mean number of pushes was $2.5 \pm 1.2$. The average diagnostic time was 46 months. Sacroiliitis was present in $73.3 \%$ of cases and the mean mSASSS score at diagnosis was $32.11 / 72$. In total, corticosteroids were used in $9(60 \%)$ of patients, NSAIDs in $26.6 \%$ while DMARDs salazopyrine and methotrexate in $33.3 \%$ and $20 \%$ of patients, respectively. Conclusion: The MICI and SpA association is undoubtedly underestimated in our regions. Better collaboration between rheumatologists and gastroenterologists could facilitate diagnosis and improve care.
\end{abstract}

\section{Keywords}

Spondyloarthritis, Chronic Inflammatory Bowel Disease, Guinea 


\section{Introduction}

Spondyloarthritis (SpA) are systemic conditions in which, apart from locomotor involvement, other organs or organ systems may also be involved [1]. These extra-articular manifestations can be divided into two groups: manifestations included in the definition of the concept of SpA, such as chronic inflammatory bowel disease (IBD), psoriasis and uveitis and those not concerned by the concept of SpA which is rather a consequence of chronic inflammation [1] [2]. The term chronic inflammatory bowel disease refers to two diseases considered idiopathic to date: Crohn's disease (CD) and ulcerative colitis (UC). Although grouped together, they are clinically, endoscopically, histologically, and etiopathogenically distinguishable from each other [1] [2] [3].

Rheumatologic involvement of IBD and reactive arthritis starting from the digestive system are part of the spondyloarthritis family [4] [5]. The frequency of HLA-B27 in the patient population with IBD is generally not increased compared to that in the general population [6] [7] [8]. Patients with IBD who have concomitantly with AS often show a significantly higher association with HLA-B27 25\% - 78\% compared to the IBD population without AS [6] [7] [9] [10] [11].

In black Africa, the prevalence of SpA associated with IBD is not clearly established [12]. Thus the objective of our study was to describe the clinical and radiological characteristics of spondyloarthritis associated with IBD.

\section{Patients and Method}

We carried out a prospective study in the rheumatology department of CHU Ignace Deen Conakry, Guinea between January and December 2019. The diagnosis of SpA was based on epidemiological, clinical and biological arguments in accordance with the criteria of Amor and ASAS. The MICIS patients were recruited from the AS population who consulted in the department during the study period.

For each patient, a survey sheet was established and the following data were collected: demographic (age, sex, history of SpA, smoking), clinical: peripheral joint involvement (mono, oligo, polyarthritis, coxites); talalgia; axial involvement (cervical, dorsal, low back pain, bilateral or tilting spessalgia), extra-articular manifestations (uveitis); biological (sedimentation rate (VS), C-reactive protein (CRP), HLA-B27 phenotyping); Radiographic sacroiliitis according to the Forestier classification, involvement of the cervical and lumbar spine according to the modified Stoke Ankylosing Spondylitis Spinal Score (mSASSS).

The diagnosis of IBD was made on the basis of clinical, endoscopic and histological arguments. The clinical characteristics of IBD were collected: the type of IBD, the average time to diagnosis, the number of attacks. Treatments (non-steroidal anti-inflammatory drugs, corticosteroids, DMARDs, anti TNFs, corticosteroid infiltrations); Disease activity was assessed according to the Bath Ankylosing Spondylitis Functional Index (BASFI), the Bath Ankylosing Spondy- 
litis Disease Activity Index (BASDAI) and Assessment in Ankylosing Spondylitis-Endorsed Disease Activity Score (ASDAS).

\section{Results}

Fifteen observations of spondyloarthritis associated with IBD were collected in patients mean age 52 years with extremes of 32 and 65 years. Nine patients $(60 \%)$ were women (Table 1). A family history of SpA was present in $11 \%$ of cases. A mixed attack (axial and peripheral) in $5(33.33 \%)$ of cases. The presence of mono, oligo, polyarthritis was $13.3 \%$, respectively; $53.33 \%$; $26.6 \%$, heel pain in $20 \%$ of cases. Coxitis was present in $11 \%$ of cases. Lumbar involvement was present in $9(60 \%)$ of cases and bilateral or tilting spessalgia in $6(40 \%)$. Uveitis was present in 2 cases. HLA B 27 phenotyping was positive in 7 (46.7\%) cases. Sacroiliitis was present in $73.3 \%$ of cases and the mean mSASSS score at diagnosis was 32.11/72.

Ten patients had Crohn's disease (CD) and 5 had ulcerative colitis (UC). The mean number of pushes was $2.5 \pm 1.2$. The average diagnostic time was 4 years. Of these patients, only $4 / 15$ saw a gastroenterologist before being seen by a rheumatologist. In total, corticosteroids were used in $9(60 \%)$ of patients, NSAIDs in $26.6 \%$ while DMARDs (salazopyrine and methotrexate in $33.3 \%$ and $20 \%$ of patients, respectively. TNF antis in $2(13,3 \%)$ of cases The evolution was favorable after a follow-up of 6 months, the BASFI and the mean BASDAI were respectively $3 / 10$ and $2.72 / 10$ (Table 1 ).

Table 1. Clinical and paraclinical characteristics of patients.

\begin{tabular}{|c|c|c|c|c|c|c|c|c|c|c|c|c|c|c|c|}
\hline & $\mathrm{P} 1$ & $\mathrm{P} 2$ & P3 & P4 & P5 & P6 & P7 & P8 & P9 & P10 & P11 & P12 & P13 & P14 & P15 \\
\hline Age (ans) & 32 & 39 & 46 & 49 & 52 & 57 & 62 & 64 & 65 & 55 & 46 & - & - & - & 58 \\
\hline Sex & $\mathrm{H}$ & $\mathrm{F}$ & $\mathrm{F}$ & $\mathrm{F}$ & $\mathrm{F}$ & F & $\mathrm{F}$ & $\mathrm{H}$ & $\mathrm{H}$ & $\mathrm{F}$ & $\mathrm{F}$ & F & $\mathrm{H}$ & $\mathrm{H}$ & $\mathrm{H}$ \\
\hline $1^{\text {st }} \mathrm{dg}$ & $\mathrm{SpA}$ & $\mathrm{SpA}$ & $\mathrm{SpA}$ & SpA & SpA & MICI & MICI & MICI & MICI & MICI & $\mathrm{SpA}$ & $\mathrm{SpA}$ & MICI & $\mathrm{SpA}$ & SpA \\
\hline Att ppq & - & + & - & + & + & - & + & + & + & + & + & + & + & + & + \\
\hline Att ax & + & + & + & + & + & + & + & - & - & + & + & - & + & + & - \\
\hline Talalgie & - & - & - & - & - & + & + & - & - & NP & NP & NP & NP & NP & $\mathrm{NP}$ \\
\hline VS/CRP & $29 / 21$ & $70 / 8$ & $14 / 2$ & $19 / 02$ & $20 / 5$ & $10 / 8$ & $68 / 6$ & $22 / 5$ & $60 / 5$ & NF & NF & NF & NF & NF & NF \\
\hline HLA B27 & + & + & - & + & - & - & - & - & + & $\mathrm{NF}$ & $\mathrm{NF}$ & $\mathrm{NF}$ & $\mathrm{NF}$ & $\mathrm{NF}$ & $\mathrm{NF}$ \\
\hline Sacroiliitis & - & - & + & + & + & + & + & - & + & & + & - & + & - & - \\
\hline Uveitis & + & - & - & - & - & - & - & - & + & - & - & - & - & - & - \\
\hline $\mathrm{MC}$ & - & - & - & + & - & + & + & - & + & + & + & + & + & + & + \\
\hline $\mathrm{RCH}$ & + & + & + & - & + & - & - & + & - & - & - & - & - & - & - \\
\hline SLZ & + & + & + & + & + & + & + & - & - & - & - & - & - & - & - \\
\hline Prednisone & + & + & + & + & + & + & + & - & - & - & - & - & - & - & - \\
\hline MTX & - & - & - & - & - & - & - & + & + & - & - & - & - & - & - \\
\hline Anti-TNF $\alpha$ & - & + & - & - & - & - & - & + & - & - & - & - & - & - & - \\
\hline
\end{tabular}

NF: not done; NP not specified, P: patient; 1st dg: first diagnosis, Att ppq: peripheral involvement; VS: sedimentation rate; CRP: C-reactive protein; MC: Crohn's disease; UC: ulcerative colitis; SLZ: salazopyrine; MTX: Methotrexate. 


\section{Discussion}

Chronic inflammatory bowel diseases are classified in the group of spondyloarthritis, they have particular characteristics that differentiate them in some aspects from idiopathic ankylosing spondylitis and other diseases in this group [13]. In sub-Saharan Africa, the prevalence of SpA associated with IBD is unclear [11] and in our study the number of cases is probably underestimated. The reason is, on the one hand, many patients have not been evaluated by a rheumatologist, and on the other hand, patients with IBD and suffering from arthralgia or back pain are not referred to rheumatology. Since gastroenterologists are, in general, unfamiliar with the diagnosis and management of joint, back and lumbar pain, it seems justified that joint complaints of IBD associated with SpA be classified according to existing rheumatological standards, thus allowing appropriate multidisciplinary management [14].

In our study, we note a female predominance, unlike other spondyloarthritis (where the male/female ratio is close to 3/1) [3]. However, other authors have reported a male predominance in patients with IBD associated with SpA [5] [15] [16] [17] [18]. This difference could be explained by the size of the sample, and the study protocols.

IBD occurs in $5 \%-10 \%$ of patients with ankylosing spondylitis (AS) and is often peripheral arthritis $(10 \%-30 \%)$ almost always affecting the lower extremities. Rarely (5\% to $15 \%$ ) of cases, they are associated with axial involvement which may precede the onset of digestive signs [5]. In our patients, peripheral involvement was present in $22.2 \%$, axial involvement in $33.3 \%$ and mixed forms in $44.4 \%$. Patients with IBD who concomitantly suffer from AS often show a significantly higher association with HLA-B27 $(25 \%-78 \%)$ compared to the IBD population without AS [6] [7] [8]. [1] [3] [7] [16] [17]. In addition, the prevalence of sacroiliitis is between $12 \%$ and $20 \%$ [19]. However, some studies have reported sacroiliitis in $20 \%-61 \%$ [3]. Other more recent studies have shown that the prevalence of axial involvement is higher than previously reported [20]-[27].

It should be noted in our study the low frequency of use of NSAIDs (26.6\%) and the higher rate of corticosteroid use (60\%). This probably reflects the fear of administering NSAIDs to patients with IBD, at risk of exacerbating intestinal symptoms. This risk, until now, remains without consensus between the proof of its implication and its true extent [3] [16] [28].

Our study had several weaknesses, the small size of our sample due to the lack of collaboration between rheumatologists and gastroenterologists. ASCA and calprotectin have not been tested. Only 3 patients received anti-TNF treatment.

\section{Conclusion}

The MICI and SpA association is undoubtedly underestimated in our regions. Better collaboration between rheumatologists and gastroenterologists could facilitate diagnosis and improve care. Further larger studies are needed to determine 
the prevalence of SpA associated with IBD.

\section{Conflicts of Interest}

The authors declare that they have no conflicts of interest.

\section{References}

[1] Kamo, K., Shuto, T. and Haraguchi, A. (2015) Prevalence of Spondyloarthritis Symptom in Inflammatory Bowel Disease Patients: A Questionnaire Survey. Modern Rheumatology, 25, 435-437. https://doi.org/10.3109/14397595.2014.964925

[2] Sanz, J., Juanola Roura, X., Seoane-Mato, D., Montoro, M., Gomollón, F., et al. (2018) Criterios de cribado de enfermedad inflamatoria intestinal y espondiloartritis para derivación de pacientes entre Reumatología y Gastroenterología. Gastroenterology \& Hepatology, 41, 54-62.

https://doi.org/10.1016/j.gastrohep.2017.03.012

[3] Resende, G.-G., Lanna, C., Bortoluzzo, B., Célio, R., Percival, G., et al. (2013) Artrite enteropática no Brasil: Dados do registro brasileiro de espondiloartrites. The Revista Brasileira de Reumatologia, 53, 452-459. https://doi.org/10.1016/j.rbr.2013.04.001

[4] Wendling, D. (2015) L'intestin des spondyloarthrites. Revue du Rhumatisme, 82, 19-22. https://doi.org/10.1016/S1169-8330(16)30068-0

[5] Shivashankar, R., Loftus, E., Tremaine, W.-J., Harmsen, S. and Zinsmeiste, A.-R. (2013) Incidence of Spondyloarthropathy in Patients with Ulcerative Colitis: A Population-Based Study. The Journal of Rheumatology, 40, 1153-1157. https://doi.org/10.3899/jrheum.121029

[6] Rudwaleit, M. and Baeten, D. (2006) Ankylosing Spondylitis and Bowel Disease. Best Practice \& Research: Clinical Rheumatology, 20, 451-471. https://doi.org/10.1016/j.berh.2006.03.010

[7] Palm, O., Moum, B., Ongre, A. and Gran, J.T. (2002) Prevalence of Ankylosing Spondylitis and Other Spondyloarthropathies among Patients with Inflammatory Bowel Disease: A Population Study (the IBSEN Study). The Journal of Rheumatology, 29, 511-515.

[8] Peeters, H., Van der Cruyssen, B., Laukens, D., et al. (2004) Radiological Sacroiliitis, a Hallmark of Spondylitis, Is Linked with CARD15 Gene Polymorphisms in Patients with Crohn's Disease. Annals of the Rheumatic Diseases, 63, 1131-1134. https://doi.org/10.1136/ard.2004.021774

[9] Podswiadek, M., Punzi, L., Stramare, R., et al. (2004) The Prevalence of Radiographic Sacroiliitis in Patients Affected by Inflammatory Bowel Disease with Inflammatory Low Back Pain. Reumatismo, 56, 110-113. https://doi.org/10.4081/reumatismo.2004.110

[10] Steer, S., Jones, H., Hibbert, J., et al. (2003) Low Back Pain, Sacroiliitis, and the Relationship with HLA-B27 in Crohn's Disease. The Journal of Rheumatology, 30, 518-522.

[11] De Vlam, K., Mielants, H., Cuvelier, C., et al. (2000) Spondyloarthropathy Is Underestimated in Inflammatory Bowel Disease: Prevalence and HLA Association. The Journal of Rheumatology, 27, 2860-2865.

[12] Jeandel, P. and Roux, H. (2002) Épidémiologie des affections rhumatologiques en Afrique subsaharienne. Revue du Rhumatisme, 69, 764-767. https://doi.org/10.1016/S1169-8330(02)00389-7

[13] Cantini, F., Niccoli, L., Nannini, C., Cassarà, E., Kaloudi, O., Rizzello, F., et al. 
(2017) Case-Control Study on Dactylitis, Enthesitis, and Anterior Uveitis in Spondyloarthritis Associated with Inflammatory Bowel Diseases: Role of Coexistent Psoriasis. The Journal of Rheumatology, 44, 1341-1346.

https://doi.org/10.3899/jrheum.161518

[14] Van Erp, S.J., Brakenhoff, L.K., Van Gaalen, A., Van den Berg, R., Fidder, H.H., et al. (2016) Classifying Back Pain and Peripheral Joint Complaints in Inflammatory Bowel Disease Patients: A Prospective Longitudinal Follow-Up Study. Journal of Crohn's and Colitis, 10, 166-175. https://doi.org/10.1093/ecco-jcc/jjv195

[15] Larsen, S., Bendtzen, K. and Nielsen, O. (2010) Extraintestinal Manifestations of Inflammatory Bowel Disease: Epidemiology, Diagnosis, and Management. Annals of Medicine, 42, 97-114. https://doi.org/10.3109/07853890903559724

[16] Collantes, E., Zarco, P., Munoz, E., Juanola, X., Mulero, J., Fernandez-Sueiro, J., et al. (2007) Disease Pattern of Spondyloarthropathies in Spain: Description of the First National Registry (REGISPONSER)-Extended Report. Rheumatology, 46, 1309-1315. https://doi.org/10.1093/rheumatology/kem084

[17] Dekker-Saeys, B.J., Meuwissen, S., Van Den Berg-Loonen, E.M., De Haas, W., Meijers, K.A. and Tytgat, G. (1978) Clinical Characteristics and Results of Histocompatibility Typing (HLA B27) in 50 Patients with Both Ankylosing Spondylitis and Inflammatory Bowel Disease. Annals of the Rheumatic Diseases, 37, 36-41. https://doi.org/10.1136/ard.37.1.36

[18] Christodoulou, D., Katsanos, K., Kitsanou, M., Stergiopouloul, C., Hatzisl, J. and Tsianos, E. (2002) Frequency of Extraintestinal Manifestations in Patients with Inflammatory Bowel Disease in Northwest Greece and Review of the Literature. Digestive and Liver Disease, 34, 781-786. https://doi.org/10.1016/S1590-8658(02)80071-8

[19] Gionchetti, P., Calabrese, C. and Rizzello, F. (2015) Inflammatory Bowel Diseases and Spondyloarthropathies. The Journal of Rheumatology, 93, 21-23.

https://doi.org/10.3899/jrheum.150628

[20] Dougados, M., van der Linden, S., Juhlin, R., Huitfeldt, B., Amor, B., Calin, A., et al. (1991) The European Spondylarthropathy Study Group Preliminary Criteria for the Classification of Spondylarthropathy. Arthritis \& Rheumatology, 34, 1218-1227. https://doi.org/10.1002/art.1780341003

[21] Turkcapar, N., Toruner, M., Soykan, I., Aydintug, O.T., Cetinkaya, H., Duzgun, N., et al. (2006) The Prevalence of Extraintestinal Manifestations and HLA Association in Patients with Inflammatory Bowel Disease. Rheumatology International, 26, 663-668. https://doi.org/10.1007/s00296-005-0044-9

[22] De Vlam, K., Mielants, H., Cuvelier, C., De Keyser, F., Veys, E.M. and De Vos, M. (2000) Spondyloarthropathy Is Underestimated in Inflammatory Bowel Disease: Prevalence and HLA Association. The Journal of Rheumatology, 27, 2860-2865.

[23] Palm, O., Moum, B., Ongre, A. and Gran, J.T. (2002) Prevalence of Ankylosing Spondylitis and Other Spondyloarthropathies among Patients with Inflammatory Bowel Disease: A Population Study (the IBSEN Study). The Journal of Rheumatology, 29, 511-515.

[24] Van Assche, G., Dignass, A., Bokemeyer, B., Danese, S., Gionchetti, P., Moser, G., et al. (2013) European Crohn's and Colitis Organisation. Second European Evidence-Based Consensus on the Diagnosis and Management of Ulcerative Colitis Part 3: Special Situations. Journal of Crohn's and Colitis, 7, 1-33.

https://doi.org/10.1016/j.crohns.2012.09.005

[25] Peluso, R., Di Minno, M.N., Iervolino, S., Manguso, F., Tramontano, G., Ambrosino, 
P., et al. (2013) Enteropathic Spondyloarthritis: From Diagnosis to Treatment. Clinical and Developmental Immunology, 2013, Article ID: 631408. https://doi.org/10.1155/2013/631408

[26] Rodríguez-Reyna, T.S., Martínez-Reyes, C. and Yamamoto-Furusho, J.K. (2009) Rheumatic Manifestations of Inflammatory Bowel Disease. World Journal of Gastroenterology, 15, 5517-5524. https://doi.org/10.3748/wjg.15.5517

[27] Orchard, T.R., Wordsworth, B.P. and Jewell, D.P. (1998) Peripheral Arthropathies in Inflammatory Bowel Disease: Their Articular Distribution and Natural History. Gut, 42, 387-391. https://doi.org/10.1136/gut.42.3.387

[28] D’Incàa, R., Podswiadekb, M., Ferronatoa, A., Punzib, L., Salvagninic, M. and Sturnioloa, G. (2009) Articular Manifestations in Inflammatory Bowel Disease Patients: A Prospective Study. Digestive and Liver Disease, 41, 565-569.

https://doi.org/10.1016/j.dld.2009.01.013 